\title{
Bioactive Compounds Evaluation of the Mudskippers in the Estuarine Area of Musi River, South Sumatera, Indonesia
}

\author{
Mohammad Rasyid Ridho ${ }^{*}$, Arum Setiawan', Sarno ', Arwinsyah', \\ Enggar Patriono', Sulistiono' \\ 1 Department of Biology, Faculty of Mathematic and Natural Sciences, Sriwijaya University, Palembang 30139, \\ Indonesia \\ * Corresponding author's e-mail: moh.rasyidridho@mipa.unsri.ac.id
}

\begin{abstract}
This research was conducted to assess various bioactive compounds in the meat of mudskippers found in the Sungsang 2 Village, Banyuasin regency, South Sumatra. The research had been synthesized using n-hexane from February to May 2018 at Agricultural Technology Production Laboratory, Sriwijaya University. Subsequently, the mudskippers (Periopthalmus chrysospilos, Boleopthalmus boddarti, and Periophthalmodon schlosseri) extract was synthesized and further investigate by conducting the GC-MS analysis. The study of bioactive compounds in mudskippers was carried out by evaporating in vacuum evaporation at $30^{\circ} \mathrm{C}$. The results showed that Periopthalmus chrysospilos has five classes of bioactive compounds such as steroids, terpenoids, carotenoids, canabinoids, and alkaloids and Boleopthalmus boddarti has five classes of bioactive compounds including steroids, carotenoids, terpenoids, bufadienolides, and carotatoxins. Furthermore, Boleopthalmus dussumieri has four classes of bioactive compounds such as steroids, carotenoids, terpenoids, and carotatoxins and Periophthalmodon schlosseri has three classes of bioactive compounds including steroids, carotenoids and terpenoids. This research discussed the potential benefit of all bioactive compounds in mudskippers for alleviating and treating children with enuresis through the review of literature on the most cited bioactive compounds.
\end{abstract}

Keywords: mudskippers, Musi river, bioactive compounds

\section{INTRODUCTION}

Mudskipper is a genus from the family of Gobiidae and subfamily Oxudercinae that is habitually known as ikan gelodok at Musi river, South Sumatera (Shukla et al., 2014; Polgar et al., 2017; Lauriano et al., 2018; Ridho et al., 2019). Mudskippers are commonly found in brackish river water and beaches with certain salinity concentration, as well as mangrove areas of the Indo-Pacific region (Tytler and Vaughan, 1983). Mudskippers are amphibious fish that are able to tolerate both fresh and marine water on muddy and sandy bottom habitat, spawning in estuarine areas (Hu et al., 2016; Hong et al., 2017). Mudskippers are also capable of spending extended periods out of water (Martin et al., 2013; Konstantinidis et al., 2016; Martinez et al., 2018). They appear during low tide, foraging on tropical mudflats, seeking mate and preserving territories for some portion of their daily cycle (Dabruzzi et al., 2019). According to the classification of amphibious gobies, 40 species of mudskippers have been currently identified in the world, which are divided into four genera of Oxudercinae, namely Boleophthalmus, Periophthalmus, Periophthalmodon and Scartelaos (Clayton 1993; Graham 1997; Graham and Wegner 2010; Ishimatsu and Gonzales 2011; Takeda et al., 2012; Murdy 2011a, You et al., 2018).

Juveniles of this Gobiidae are herbivores that eat more diatoms and filamentous algae, while the major food of adult Gobiidae are crustaceans $(95.5 \%)$, polichaetas $(86.4 \%)$ and land insects (85\%) (Bob-Manuel, 2011). The burrows of these habitats are categorically suitable for the mudskippers for feeding grounds, spawning 
areas and nursery grounds (Masuda et al., 1984; Bob-Manuel, 2011; Satapoomin and Poovachiranon, 1997; Redjeki, 2013). Mudskippers are commonly consumed and employed in traditional medicine in many countries such as China, Malaysia and Japan (Feulner 2013; Gadhavi et al., 2017; Ikram et al., 2010; looi et al., 2016 and Yang, X. X., 2017). The medicinal mudskippers were often prepared from the natural products which contain different bioactive compounds (Mahadevan et al., 2019; Wu et al., 2009). On the other hand, many fishermen and general public around the Musi river ignore the existence and benefits of mudskippers.

Corticosteroids, one of bioactive compounds in mudskippers, are steroid hormone class for overcoming inflammations (Panda and Mabalirajan, 2018; Heughten et al., 2018). These hormones are a contributing factor to alleviating enuresis (bedwetting) in child. Enuresis is most common among children or young persons and is denoted by repeated voiding of urine into the bed or clothing (Apos et al., 2017 and Shafi et al., 2019). The study area corresponded to bioactive compounds like corticosteroid compounds in mudskippers that can reduce the enuresis problem in children (Jain et al., 2016). The authors intended to evaluate the bioactive compounds in the four species mudskippers including Periophthalmus chrysospilos, Boleopthalmus boddarti, Boleopthalmus dussumieri and Periophthalmodon schlosseri.

\section{MATERIALS AND METHODS}

\section{Fishes and experimental design}

Mudskippers were obtained from an estuarine area around the Sungsang 2 village, Banyuasin regency, South Sumatera. Mudskippers, apparently healthy, were randomly caught using fishing equipment and transported to the Agricultural Technology Production Laboratory, Sriwijaya University for cleaning and removing the bones from the fish. After the filleting process, the mudskippers were divided into four groups with Periophthalmus chrysosphilos (8 grams), Boleopthalmus boddarti (100 grams), Boleopthalmus dussumieri (13.8 grams) and Periophthalmodon schlosseri (100 grams) which were homogenized.
The crushed fish flesh dissolved in n-hexane solvent with a sample ratio of 1: 4 and macerated for 24 hours. The next step involved filtering with calico cloth and filter paper and evaporating with vacuum evaporator at $30^{\circ} \mathrm{C}$ with a speed of $200 \mathrm{rpm}$. Each extract sample was reconstituted using $\mathrm{n}$-hexane solvent, then each $1 \mu \mathrm{L}$ was taken to be injected and analyzed in GC-MS alternately.

\section{Analysis technique}

The data in this research were expressed in the form of chromatograms that contain graphs and were equipped with a list of detected chemical compounds, along with the structure of compounds, retention times, areas, and probability of the compound types. The data analysis was performed by identifying the chemical compounds detected to find out the natural name (nature of compound name), synonym, and the class of compounds of these chemical compounds. Identification was done by comparing the compound name detected with a data base on the literature in the form of books and journals. The studies reported as full-text articles, those published as abstracts only and unpublished data were included as well.

\section{Gas chromatography and mass spectroscopy (GC-MS) analysis}

The qualitative analyses of the mudskipper extract were expressed with a GCMS-QP 2010 Plus (Shimadzu, Japan) system equipped under computer control at $70 \mathrm{eV}$ (Mohammed and Imad, 2013). The methanol extract in the amount of $1 \mu 1$ was entered into the GC-MS with a micro injector and followed by scanning for $45 \mathrm{~min}$. The temperature was maintained in the oven at $100^{\circ} \mathrm{C}$ and Helium gas was utilized as a carrier as well as an eluent. The helium flow was arranged to $1 \mathrm{ml}$ per min and electron energy was fired by a mass detector about $70 \mathrm{eV}$. The compound of elite 1 was used as separation column (100\% dimethyl poly siloxane) (Hameed et al., 2016; Kareem et al., 2015). The identity of the compounds in the extracts was assigned by the comparison of their retention indices and mass spectra fragmentation patterns with those stored on the computer library and also with the data published in the literature. The compounds were identified by comparing their spectra to those of the Wiley and NIST/EPA/NIH mass spectral libraries. 


\section{RESULTS AND DISCUSSIONS}

\section{GC-MS results of the periopthalmus chrysospilos extract}

The gas chromatography and mass spectroscopy analysis of bioactive compounds were carried out in the Periopthalmus chrysospilos extract that was presented in Figure 1. It can be seen that the vertical lines in the chromatogram pattern point out the short periods of time when the ion beam is deflected-off the plate (and thus off the beam monitor) which is necessary when changing the position of the photographic plate, a process that takes about 2-3 seconds with the present arrangement. This pen deflection creates a useful signal of the exact quantities of the chromatogram being noted with the mass spectrometer and facilitates the reconnection of the spectra on the plate with the chromatogram.

The GC-MS chromatogram showed that the presence of five major peaks of bioactive compounds was detected and the components corresponding to the peaks were determined as follows. The highest peak in chromatogram pattern could be seen that the extract of Periopthalmus chrysospilos has retention time 14.44 minutes. On the basis of the GC-MS signal, the sample has many bioactive compounds which were indicated by the signals detected. It shows that the GC-MS analysis successfully proves that the Periopthalmus chrysospilos extract is suitable for treating the people with inflammatory diseases, especially enurosis.

\section{Bioactive compounds in the Periopthalmus chrysospilos extract}

The results of Periopthalmus chrysospilos extract revealed the amounts of bioactive compounds such as terpenoids, alkaloids, steroids, carotenoids and canabinoids. As many as 4 types of terpenoid compounds were detected, with a total of 4 compounds. One type of carotenoid compounds was detected with a total of 4 compounds. Additionally, one type of canabinoid compounds was detected with a total of 2 compounds; and 1 alkaloid compound was detected with a total of 1 compound. The cannabinoid bioactive compounds were also detected in this sample with a total of 1 compound. Cannabinoid compounds include secondary metabolites which are usually found in cannabis plants. According to Maggyvin and Sinuraya (2017), cannabinoids are classified by source and origin. Phytocannabinoids are derivative compounds from cannabis and other plants, including delta-9-tetrahydrocannabinol (THC), cannabidiol (CBD), and cannabinol (CBN). The details of Boleopthalmus boddarti extract were elucidated in the Table 1.

The highest amount of bioactive compounds in Periopthalmus chrysospilos extract corresponded to the steroid compounds; as many as 10 types of compounds were detected with a total of 24 compounds. The total number of compounds detected are named Androst7-ene-6,17-dione, 2,3,14-trihydroxy-, where the total amount of compounds is 10 compounds. According to Moss (1989), androstane is an anabolic steroid group that belongs to the basic carbon cycle, which is unsaturated and is an alkyl substitute in the 17 th carbon chain.

\section{GC-MS Results of the Boleopthalmus boddarti extract}

The result of GC-MS analysis of Boleopthalmus boddarti extract was described as the chromatogram form for all chemical compounds that were read by the detector (Fig. 2). The vertical lines were found in this chromatogram

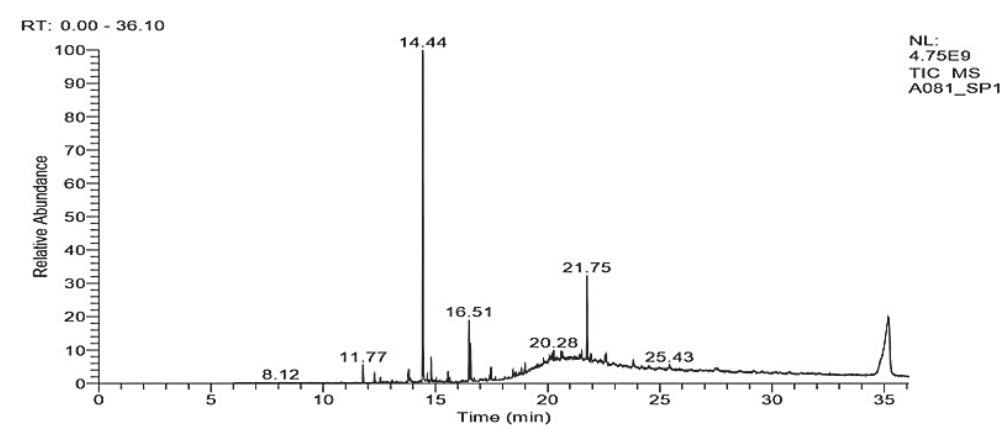

Figure 1. Chromatogram result of peak chemical compounds in Periopthalmus chrysospilos

(Source: LHP, 2018) 


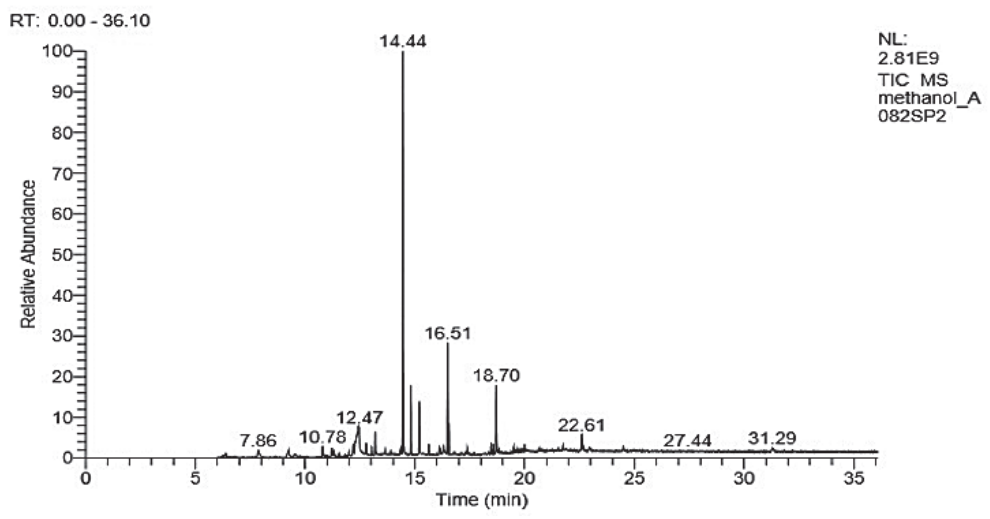

Figure 2. Chromatogram result of peak chemical compounds in Boleopthalmus boddarti

(Source: LHP, 2018)

Table 1. The amount of bioactive compounds in the Periopthalmus chrysospilos extract

\begin{tabular}{|c|l|c|c|}
\hline No. & \multicolumn{1}{|c|}{ Compound names } & Compound classes & $\begin{array}{c}\text { Total } \\
\text { numbers }\end{array}$ \\
\hline 1. & D-Limonene & Terponoids & 1 \\
\hline 2. & Limonene & Terponoids & 1 \\
\hline 3. & Aspidospermidin-17-ol, 1-acetyl-19,21-epoxy-15, 16-dimethoxy- & $\begin{array}{c}\text { Alkaloids } \\
\text { (Aspidospermidin) }\end{array}$ & 1 \\
\hline 4. & Choltesan-3-ol, 2-methylene- & Steroids & 6 \\
\hline 5. & Azulene, 1,4-dimethyl-7-(1-methylethyl)- & Terpenoids & 1 \\
\hline 6. & 17.alfa.,21á-28, 30-Bisnorhopane & Steroids & 1 \\
\hline 7. & 4-Androsten-6á-ol-3,17-dione & Steroids & 3 \\
\hline 8. & 3,9-Epoxypregn-16-ene-14,20-diol, 7,11,18-triacetoxy-3-methoxy- & 1 \\
\hline 9. & Cholestan-26-oic acid, 3,7,12-trihydroxy- & Steroids & 1 \\
\hline 10. & Rhodopin & Steroids & 1 \\
\hline 11. & Cannabinol, trifluoroacetate & Cannabinoids & 4 \\
\hline 12. & Cholestan-3,5-diol, 5-acetate & Steroids & 2 \\
\hline 13. & $\begin{array}{l}\text { Milbemycin B, 5-demethoxy-5-one-6,28-anhydro-25-ethyl-4-methyl-13-chloro- } \\
\text { oxime }\end{array}$ & Steroids & 1 \\
\hline 14. & 9,19-Cyclolanostan-3-ol, 24,24-epoxymethano-acetate & Terpenoids & 1 \\
\hline 15. & $\begin{array}{l}\text { 8,14-Seco-3,19-epoxyandrostane-8,14-dione,17-acetoxy-3 á-methoxy-4,4- } \\
\text { dimethyl- }\end{array}$ & Steroids & 11 \\
\hline 16. & Androst-7-ene-6,17-dione, 2,3,14-trihydroxy- & Steroids & 10 \\
\hline 17. & $\begin{array}{l}\text { 2-Phenanthrenecarboxylic acid, 1-(1,3-dithian-2-ylmethyl)-7-hydroxy-2,4b- } \\
\text { dimethyl-1,2,3,4,4a,4b,5,6,7,8,10,10a-dodecahydro-,methyl ester }\end{array}$ & Steroids & 1 \\
\hline & & & 1 \\
\hline
\end{tabular}

pattern. Those indicate more than one bioactive compound in the Boleopthalmus boddarti extract. The presence of five major peaks of bioactive compounds was detected and the most compound are from steroids. The highest peak in chromatogram pattern could be seen that the Boleopthalmus boddarti extract has retention time of 14.44. On the basis of the GC-MS signal, the sample has many bioactive compounds, which was shown by some signals detected. It shows that the Boleopthalmus boddarti extract can be successfully used for treating people with inflammatory diseases, especially enuresis, as proven by the GC-MS analysis.

\section{Bioactive compounds in the Boleopthalmus boddarti extract}

The results of Boleopthalmus boddarti extract revealed the amounts of bioactive compounds such as steroids, carotenoids, terpenoids, bufadienolide, carotatoxin, cholesterol, and corticosteroid shown in Table 2. The compounds of steroid groups were detected as many as 24 types of compounds with a total of 44 compounds. Specific steroid compounds, namely corticosteroids, were detected with 2 types of compounds and a total of 3 compounds. The details of Boleopthalmus boddarti extract were elucidated in Table 2. 
Corticosteroids are drugs containing steroid hormones that are useful in increasing the needed steroid hormones in the body, relieving inflammation and helping in alleviate asthma, allergy and multiple sclerosis (Cidlowski, 2013; Panda and Mabalirajan, 2018; Rozaliyani, 2011). According to the analysis of Prasad et al. (2018), corticosteroids also reduce the mortality risk from tuberculosis effect at least in the short term. A quite unique compound, called Gamabufotalin, was detected in the Boleopthalmus boddarti extract; it is a bioactive compound of the bufadienolide type. According to Dmitrieva et al. (2000), Bufadienolides are biosynthetic steroids that are independent of the side chain of cholesterol division. Bufadienolides (BDs) also include the corticic steroid groups, which are usually obtained from amphibian poison extracts, these compounds are often used as traditional medicine in Asia.

\section{GC-MS Results of Boleopthalmus dussumieri extract}

The result of the GC-MS analysis of Boleopthalmus dussumieri extract was described as the chromatogram form for all chemical compounds that were read by the detector (Fig. 3). The vertical lines were found in this chromatogram pattern. Those indicate more than one bioactive compound in the Boleopthalmus dussumieri extract. The presence of four major peaks of bioactive compounds was detected by GC-MS like steroids, terpenoids,

Table 2. The amount of bioactive compounds in the Boleopthalmus boddarti extract

\begin{tabular}{|c|c|c|c|}
\hline No. & Compound names & Compound classes & $\begin{array}{c}\text { Total } \\
\text { numbers }\end{array}$ \\
\hline 1. & Curan-17-oic acid, 19,20-dihydroxy-, methyl ester & Steroids & 2 \\
\hline 2. & Cholestan-3-ol, 2-methylene- & Steroids & 12 \\
\hline 3. & Citronellol epoxide & Terpenoids & 1 \\
\hline 4. & Falcarinol & $\begin{array}{l}\text { Carotatoxin (secondary } \\
\text { cancer anti metabolites) }\end{array}$ & 1 \\
\hline 5. & Cholestan-3-one, cyclic 1,2-ethanediyl aetal & Steroids & 1 \\
\hline 6. & ..psi.,.psi.-Carotene, 1,1',2,2'-tetrahydro-1,1'-dimethoxy & Carotenoids & 8 \\
\hline 7. & Androsten-4-en-11-ol-3,17-dione, 9-thiocyanato- & Steroids & 2 \\
\hline 8. & Androsten-5-en-17-one-3,11-bis[(trimethylsilyl)oxy]-, O-(phenylmethyl)oxime & Steroids & 1 \\
\hline 9. & Prosta-5,13-dien-1-oic acid, 9,11,15-tris[(trimethylsilyl)oxy]-, trimethylsilyl ester & Steroids & 6 \\
\hline 10. & Rhodoxanthin & Carotenoids & 2 \\
\hline 11. & Rhodopin & Carotenoids & 2 \\
\hline 12. & $\begin{array}{l}\text { 5á-Ergost-24-en-26-oic acid, 5,6á-epoxy-4á, 18,22-trihydroxy-3-methoxy-1-ox } \\
\text { o-, ë-lactone, diacetate, }\end{array}$ & Steroids & 1 \\
\hline 13. & Ethyl iso-allocholate & Steroids & 1 \\
\hline 14. & Gamabufotalin & $\begin{array}{l}\text { Bufadienolide (stereoid } \\
\text { aglycones in frogs) }\end{array}$ & 1 \\
\hline 15. & Betamethasone acetate & Corticosteroid & 2 \\
\hline 16. & Cholestan-26-oic acid, 3,7,12-trihydroxy- & Steroids & 2 \\
\hline 17. & ..psi.,.psi.-Carotene, 3,4-didehydro-1,2,7',8'-tetrahydro-1- methoxy-2-ox o & Carotenoids & 1 \\
\hline 18. & ..psi.,.psi.-Carotene, 3,3',4,4'-tetrahydro-1',2'-dihydro-1-hydroxy-1'methoxy & Carotenoids & 1 \\
\hline 19. & Prosta-5,13-dien-1-oic acid, 9,11,15-tris[(trimethylsilyl)oxy]-, trimethylsilyl ester & Steroids & 2 \\
\hline 20. & $\begin{array}{l}\text { 17á-Acetoxy-1',1'-dicarboethoxy-1á,2á-dihydrocy cloprop[1,2]-5á-androst-1- } \\
\text { en-3-one }\end{array}$ & Steroids & 2 \\
\hline 21. & Cholesterol & Cholesterol & 1 \\
\hline 22. & 26-Nor-5-cholesten-3á-ol-25-one & Steroids & 1 \\
\hline 23. & $\begin{array}{l}\text { 17-(1,5-Dimethylhexyl)-10,13-dimethyl-2,3,4,7,8,9,10,11,12,13,14,15,16,17- } \\
\text { tetradecahydro-1Hcyclopenta[a]phenanthren-3-ol }\end{array}$ & Steroids & 1 \\
\hline 24. & Androst-4-en-9-thiocyanomethyl-11-ol-3,17-dione & Steroids & 1 \\
\hline 25. & Androst-5-en-3-one, 19-acetoxy-4,4-dimethyl-,oxime & Steroids & 1 \\
\hline 26. & $\begin{array}{l}\text { 3-Isopropyl-6a,7,10b-trimethyl-8-(2-oxo-2-phenylethyl)dodecahydrobenzo[f] } \\
\text { chromene-7-carboxylic acid, methyl ester }\end{array}$ & Corticosteroid & 1 \\
\hline 27. & Androst-8-en-3-ol, 4,4,14á-trimethyl-17-(2-bromo-1-methylethyl) & Steroids & 1 \\
\hline 28. & $\begin{array}{l}\text { 1',1'-Dicarboethoxy-1á,2á-dihydro-3'H-cycloprop[1,2]cholesta-1,4,6-trien-3- } \\
\text { one }\end{array}$ & Steroids & 1 \\
\hline 29. & $\begin{array}{l}\text { Prosta-5,13-dien-1-oic acid, 9,11,15,19-tetrakis[(trimethylsilyl)oxy]-, methyl } \\
\text { ester }\end{array}$ & Steroids & 1 \\
\hline
\end{tabular}




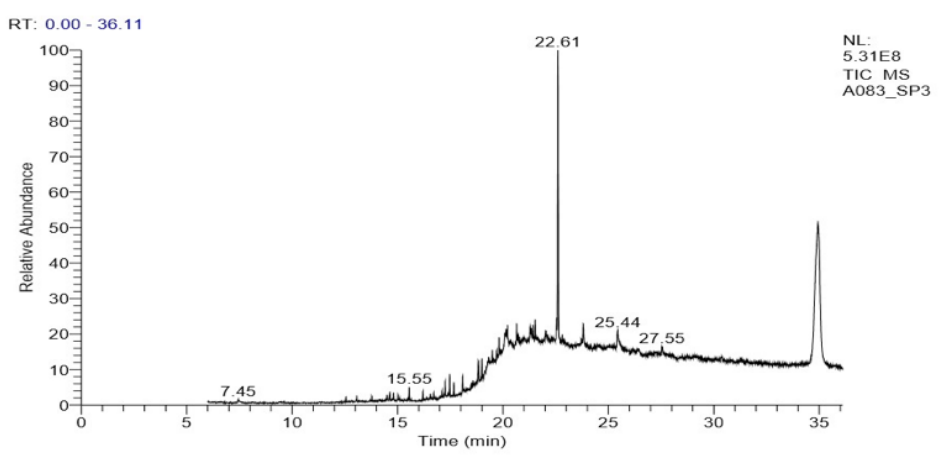

Figure 3. Chromatogram result of peak chemical compounds in Boleopthalmus dussumieri (Source: LHP, 2018)

carotenoids and carotatoxins. The highest peak in the chromatogram pattern could be seen that Boleopthalmus dussumieri extract has retention time of 22.61. On the basis of the GC-MS signal, the sample has significant bioactive compounds, which was shown in Table 3.

\section{Bioactive compounds in the Boleopthalmus dussumieri extract}

The bioactive compounds detected from the Boleopthalmus dussumieri extract include steroids, terpenoids, carotenoids and carotatoxins. The compounds of steroid classes include as many as 11 types of compounds, with a total of $26 \mathrm{com}$ pounds. The group of carotenoid compounds was detected in as many as 6 types of compounds, with a total of 13 compounds. The group of terpenoid compounds was detected by 2 types of compounds, with a total of 2 compounds. The carotatoxin compounds were also detected in the Boleopthalmus dussumieri extract, with a total of 1 compound. The details of Boleopthalmus dussumieri extract were elucidated in Table 3.

The name of steroid compounds with the highest total number of compounds is Spirost-8-en11-one, 3-hydroxy. According to Rajendran et al. (2017), Spirost-8-en-11-one, 3-hydroxy included the steroid compounds which have an anti-cancer bioactivity. Spirost-8-en-11-one, 3-hydroxy has the chemical formula $\mathrm{C} 27 \mathrm{H} 40 \mathrm{O} 4$. The group of carotenoid compounds detected with the highest amount is Rhodopin, where the total amount of these compounds is 5 compounds. According to Komori et al. (1998), Rhodopin is a carotenoid compound which is usually produced by Rhodosiprillum rubrum bacteria with the chemical formula $\mathrm{C} 40 \mathrm{H} 58 \mathrm{O}$.
Bioactive carotatoxin alkaloids were also detected in the Boleopthalmus dussumieri extract. The name of the carotatoxin group is falcarinol and the total of compound is only 1 compound. According to Zaini et al. (2012), falcarinol (FaOH) is one of the compounds found in carrots; this compound has shown bioactive action in several types of cell cultures. Falcarinol has been shown to be cytotoxic to the culture of acute lymphoblastic leukemia cells.

\section{GC-MS Results of the Periopthalmodon schlosseri extract}

The result of GC-MS analysis of Periopthalmodon schlosseri extract was described as the chromatogram form for all chemical compounds that was read by the detector (Fig. 4). The vertical lines were found in this chromatogram pattern. Those indicate more than one bioactive compound in Boleopthalmus boddarti extract. The presence of five major peaks of bioactive compounds was detected and the most compound are from steroids. The highest peak in the chromatogram pattern indicated that the Boleopthalmus boddarti extract has retention time of 14.44. On the basis of the GC-MS signal, the sample has many bioactive compounds which was shown by some signals detected. It shows that the GC-MS analysis proves that the Boleopthalmus boddarti extract can be successfully used for treating people with inflammatory diseases especially enurosis.

\section{Bioactive compounds in the Periopthalmodon Schlosseri extract}

The bioactive compounds detected from Periopthalmodon schlosseri extract including steroids, carotenoids and terpenoids. As many as 
Table 3. The amount of bioactive compounds in the Boleopthalmus boddarti extract

\begin{tabular}{|c|l|c|c|}
\hline No. & \multicolumn{1}{|c|}{ Compound names } & Compound classes & $\begin{array}{c}\text { Total } \\
\text { numbers }\end{array}$ \\
\hline 1. & Limonene & Terpenoids & 1 \\
\hline 2. & D-Limonene & Terpenoids & 1 \\
\hline 3. & Corynan-17-ol, 18,19-didehydro-10-methoxy-,acetate (ester) & Steroids & 2 \\
\hline 4. & Rhodopin & Carotenoids & 5 \\
\hline 5. & C-Sitosterol & Steroids & 1 \\
\hline 6. & Spirost-8-en-11-one, 3-hydroxy & Steroids & 13 \\
\hline 7. & Cholest-5-en-3-ol, 24-propylidene- & Steroids & 2 \\
\hline 8. & Stigmasta-5,24(28)-dien-3-ol & Steroids & 1 \\
\hline 9. & ..psi.,.psi--Carotene, 1,1',2,2'-tetrahydro-1,1'-dimethoxy & Carotenoids & 4 \\
\hline 10. & $\begin{array}{l}\text { 5á-Ergost-24-en-26-oic acid, 5,6á-epoxy-4á, 18,22-trihydroxy-3-methoxy-1- } \\
\text { ox o-, ë-lactone, diacetate, }\end{array}$ & Steroids & 1 \\
\hline 11. & ..psi.,.psi.-Carotene, 3,4-didehydro-1,2,7',8'-tetrahydro-1-methoxy-2-ox o & Carotenoids & 1 \\
\hline 12. & 5-Chloro-6beta-nitro-5alpha-cholestan-3-one & Steroids & 1 \\
\hline 13. & $\begin{array}{l}\text { Prosta-5,13-dien-1-oic acid, 9,11,15-tris[(trimethylsilyl)oxy]-, trimethylsilyl } \\
\text { ester }\end{array}$ & Steroids & 1 \\
\hline 14. & Cholest-4-ene, 3á-(methoxymethoxy)- & Steroids & 1 \\
\hline 15. & Rhodoxanthin & Carotenoids & 1 \\
\hline 16. & 4'-Apo-á,.psi--carotenoic acid & Carotenoids & 1 \\
\hline 17. & Astaxanthin & Carotenoids & 1 \\
\hline 18. & Androst-7-ene-6,17-dione, 2,3,14-trihydroxy & Steroids & 2 \\
\hline 19. & Prosta-5-en-1-oic acid, 9,11,15-tris[(trimethylsilyl)oxy]-, methylsilyl ester & Steroids & 1 \\
\hline 20. & Falcarinol & Carotatoxin & 1 \\
\hline
\end{tabular}

11 bioactive steroid compounds were detected, with a total of 21 compounds; 3 types of the carotenoid group compounds, with a total of 6 compounds; while only 1 type of terpenoid group compounds were detected with a total of 1 compound. The details of the Periopthalmodon schlosseri extract were elucidated in Table 4.

The steroid compounds in the Periopthalmodon schlosseri extract are named Cholestan3-ol, 2-methylene-, Cholest-5-en-3-ol (3á) -, tetradecanoate, Cholesta-3,5-diene, Cholesteryl benzoate, 17.alfa., 21á-28, 30-Bisnorhopane, Cholesterol, 26-Nor-5-cholesten-3á-ol-25-one, Cholestane-3,5-diol, 5-acetate, Campesterol, Ergost-5-en-3-ol, and Androst- 7-ene-6,17-dione, 2,3,14-trihydroxy-. According to Salempa and Muharram (2016), steroids are natural compounds which consist of a carbon skeleton and comprise three circles of six perdidro phenanthrene fused into one circle of five. Saturated-click hydrocarbons have a circumference system consisting of 17 carbon atoms.

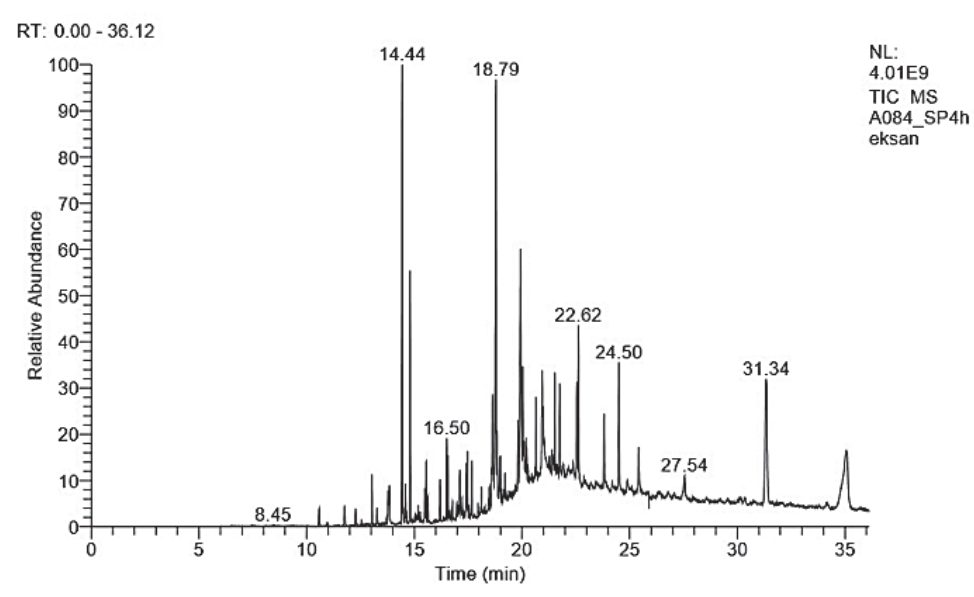

Figure 4. Chromatogram result of peak chemical compounds in Periopthalmodon schlosseri

(Source: LHP, 2018) 
Table 4. The amount of bioactive compounds in the Periopthalmodon schlosseri extract

\begin{tabular}{|c|l|c|c|}
\hline No. & \multicolumn{1}{|c|}{ Compound names } & Compound classes & Total numbers \\
\hline 1. & D-Limonene & Terpenoids & 1 \\
\hline 2. & Cholestan-4-ol, 2-methylene- & Steroids & 4 \\
\hline 3. & Cholest-5-en-3-ol (3á)-, tetradecanoate & Steroids & 1 \\
\hline 4. & Cholesta-3,5-diene & Steroids & 1 \\
\hline 5. & Cholesteryl benzoate & Steroids & 1 \\
\hline 6. & Rhodopin & Carotenoids & 3 \\
\hline 7. & Azafrin & Carotenoids & 1 \\
\hline 8. & 17.alfa.,21á-28,30-Bisnorhopane & Steroids & 2 \\
\hline 9. & Cholesterol & Steroids & 2 \\
\hline 10. & 26-Nor-5-cholesten-3á-ol-25-one & Steroids & 1 \\
\hline 11. & Cholestane-3,5-diol, 5-acetate & Steroids & 1 \\
\hline 12. & Campesterol & Steroids & 1 \\
\hline 13. & Ergost-5-en-3--ol & Steroids & 1 \\
\hline 14. & Astaxanthin & Carotenoids & 2 \\
\hline 15. & Androst-7-ene-6,17-dione, 2,3,14-trihydroxy- & Steroids & 6 \\
\hline
\end{tabular}

D-Limonene is the only the group of terpenoid compounds which was detected in the Periopthalmodon schlosseri extract. This compound was also detected in samples of Periopthalmus chrysospilos extract and Boleopthalmus dussumieri extract. According to Sun (2007), D-Limonene is a monocyclic terpenoid with a lemon-like odor and is a major constituent of several essential oils of Citrus sp. (orange, lemon, mandarin, lime and grapefruit). D-Limonene is widely used as an additive (additive) in perfumes, soap, food, gum and drinks. This compound is also listed in the Code of Federal Regulation as a material that is known to be safe or generally recognized as safe (GRAS) as a flavoring agent.

The group of carotenoid compounds detected includes rhodopin, azafrin and astaxanthin. The rhodopin compounds were detected in all samples with a sufficient number of total compounds in each sample. The astaxanthin compounds were also detected in the flesh extracts of Boleopthalmus boddarti and Boleopthalmus dussumieri, with a total of 1 compound each in each sample. In turn, the azafrin compounds were only detected in Periopthalmodon schlosseri extract. According to Gopalakrishnan and Kalaiarasi (2012), azafrin is a compound of the carotenoid ester group with the molecular formula $\mathrm{C} 28 \mathrm{H} 40 \mathrm{O} 4$. The azafrin compounds include the bioactive compounds that have the potential as antioxidants, anti-inflammatory, anticancer, anti-criticism, natural dyes, eye pain medications, and as compounds that can reduce hypertension.

\section{Physical and chemical properties of the environment at sampling locations}

The main point of mudskippers sampling based on the GPS is in the coordinates $\mathrm{S} 02^{\circ}$ $21^{\prime} 57.5$ "E $104^{\circ} 54^{\prime} 00.1$ ". The environment measurements of the physical and chemical properties were carried out at the main point of sampling and obtained as presented in Table 5.

The measurement of the physical and chemical properties of the environment was carried out at 3 different times. The first measurements were made in late March, precisely in the afternoon, and obtained soil moisture data of $100 \%$, soil $\mathrm{pH}$ of 6.5 , water $\mathrm{pH}$ of 6.82 , and water salinity of $0.1 \%$. The second measurement was carried out in an April morning and $100 \%$ of soil moisture was obtained, soil $\mathrm{pH}$ was 6.5 , water $\mathrm{pH}$ was 7.32 , and water salinity was $0 \%$. The third measurement was carried out in the afternoon of April and obtained 100\% soil moisture data, a soil $\mathrm{pH}$ of 6.5 , a water $\mathrm{pH}$ of 6.7 , and water salinity of $0 \%$.

Table 5. Physical and chemical properties of the environment at the sampling location

\begin{tabular}{|c|c|c|c|}
\hline \multirow{2}{*}{ Parameter } & \multicolumn{3}{|c|}{ Measurement Time } \\
\cline { 2 - 4 } & March & April Morning & $\begin{array}{c}\text { April } \\
\text { Afternoon }\end{array}$ \\
\hline $\begin{array}{c}\text { Soil moisture } \\
(\%)\end{array}$ & 100 & 100 & 100 \\
\hline Soil pH & 6.5 & 6.5 & 6.5 \\
\hline Water pH & 6.82 & 7.32 & 6.7 \\
\hline $\begin{array}{c}\text { Waters } \\
\text { salinity (\%) }\end{array}$ & 0.1 & 0 & 0 \\
\hline
\end{tabular}


On the basi of the data of the physical and chemical properties of the environment, it can be seen that the soil moisture at the main sampling point shows $100 \%$ at 3 times measurements with different times. This shows that the sampling location has a substrate in the form of mud which is always wet. According to Kurnia et al. (2006), the soil moisture is one of the key variables in the hydrological process that plays an important role in determining the availability of water as a very fundamental element in the life of living things. The $100 \%$ soil moisture indicates that the soil is saturated with water.

The water salinities at 3 measurements with different times showed the numbers $0.1 \%$, $0 \%$ o and $0 \%$. This shows that the waters around the sampling location tend to be tasteless. According to Masuda et al. (1984) and Redjeki (2013), the gudder is an amphidromous demersal fish that tolerates freshwater and sea, lives on muddy and sandy bottom and spawns in estuarine areas.

\section{CONCLUSIONS}

The bioactive compound analysis of the Periopthalmus chrysospilos extract showed that it consists of steroids, terpenoids, carotenoids, canabinoids, and alkaloids. As many as 10 types of hormones were found in the Periopthalmus chrysospilos extract, with a total of 24 compounds. The Boleopthalmus boddarti extract comprised steroids, carotenoids, terpenoids, bufadilenoid, and carotatoksin. There were 24 types of compounds detectedwith a total of 44 compounds in the Boleopthalmus boddarti extract. The Boleopthalmus dussumieri extract has bioactive compounds from the groups of steroids, carotenoids, terpenoids, and carotatoksin. The Boleopthalmus dussumieri extract has as many as 11 types of compounds with a total of 26 compounds. The Periopthalmodon schlosseri extract contained the bioactive compounds including steroids, carotenoids and terpenoids. As many as 11 types of compounds were detected with a total of 21 compounds. The higher concentrations of bioactive compounds were found in the mudskippers that are possibly consumed for treating inflammatory diseases, enuresis in children and allergy.

\section{Acknowledgments}

The authors would like to thank Dr. Arum Setiawan and Sulistiono, Dr. Sarno, Dr. Arwinsyah,
Enggar Patriono' M.Si., College of Agricultural Technology Production Laboratory, Sriwijaya University for his help in specimen preparation. We also thank anonymous referees for constructive criticism on the manuscript. This work was supported by the projects of Kemenristekdikti.

\section{REFERENCES}

1. Bob-Manuel, F.G., 2011. Food and feeding ecology of the mudskipper Periophthamus koelreuteri (Pallas) Gobiidae at Rumuolumeni Creek Niger Delta, Nigeria. Agriculture and Biology Journal of North America. 2, 897-901.

2. Clayton DA. 1993. Mudskippers. Oceanogr Mar Biol Annu. Rev 31:507-77.

3. Dabruzzi, T. F., Fangue, N. A., Kadir, N. N, and Bennett, W. A., 2019. Thermal Niche Adaptations of Common Mudskipper (Periophthalmus kalolo) and Barred Mudskipper (Periophthalmus argentilineatus) in Air and Water. Journal of Thermal Biology. 81, 170-177.

4. DKP Provinsi Sumatera Selatan, 2017. Sumberdaya: Pengelolaan Pesisir Provinsi Sumatera Selatan 1. [online] Tersedia: dislutkan.sumselprov.go.id/ page/38/sumberdaya\#. [11 November 2017].

5. Dmitrieva, R. I. Bagrov, A. Y., Lalli, E., SassoneCorsi, P., Stocco, D., dan Doris, P. A., 2000. Mamalian Bufadienolide is Synthesized from Cholesterol in the Adrenal Cortex by Pathway that is Independent of Cholesterol Side-chain Cleavage Hypertention. 36, 3, 442-8.

6. Feulner, G. R., and Binish R, 2013. Re-discovery of the mudskipper Periophthalmus waltoni Koumans, 1941 in the United Arab Emirates. Tribulus, vol. 21, 2013, p. 42+. Gale Academic Onefile, Accessed 13 Oct. 2019

7. Gadhavi, M.K., Kukadia, D., Dar, S., Gokulakannan, N., Talukdar, G., Sivakumar, K., and Gopi, G. V., 2017. Indigenous techniques of catching mudskipper in Bhavnagar and Bharuch districts, Gujarat. Indian Journal of Traditional Knowledge. 16(3), pp. 533-538.

8. Gopalakrishnan, S., and Kalaiarasi, T., 2012. Identification of Chemical Compound from the Fruits of Cucumis trigonus Roxb. By GC-MS Analysis. International Journal of Phytopharmacy. 2 (5) 122-128.

9. Graham, J. B., 1997. Air-breathing fishes: evolution, diversity, and adaptation. San Diego: Academic Press. p. 299.

10. Graham, J. B., and Wegner, N. C., 2010. Breathing air in water and in air: the air-breathing fishes. In: Nilsson GE, editor. Respiratory physiology of vertebrates: life with and without oxygen. Cambridge: 
Cambridge University Press. p. 174-221.

11. Hameed, I. H., Jebor, M. A., and Ommer, A. J., 2016. Haplotype data of mitochondrial DNA coding region encompassing nucleotide positions $11,719-12,184$ and evaluate the importance of these positions for forensic genetic purposes in Iraq. Mitochondrial DNA Part A. 27(2), 1324-1327.

12. Huang, M. C., and Lee C. L., 2019. Thermostability of tropomyosins from the fast skeletal muscles of tropical fish species. Fish Physiology and Biochemistry. 45, 1189-1202.

13. Hu, W., Zhang. J., Kang, B., 2016. Structure and function of corneal surface of mudskipper fishes. Fish Physiology and Biochemistry. 42, 1481-1489.

14. Ikram, M. M., Ismail, A., Yap, C. K., and Azwady, A. A. N., 2013. Levels of heavy metals (Zn, Cu, $\mathrm{Cd}$, and $\mathrm{Pb}$ ) in mudskippers (Periophthalmodon schlosseri) and sediments collected from intertidal areas at Morib and Remis, Peninsular Malaysia. Toxicology \& Environmental Chemistry. 92(8), 1471-1486.

15. Ishimatsu, A., andGraham, J. B., TT. 2011. Mudskippers: front runners in the modern invasion of land. In: Patzner R, Van Tassell JL, Kovac M, Kapoor BG, editors. The biology of gobies. Enfield: Science Publishers. p. 603-32.

16. Kareem, M. A., Abdulzahra, A. I., Hameed, I. H., and Jebor, M. A., 2015. A New Polymorphic Positions Discovered in Mitochondrial DNA Hypervariable Region HVIII From Central and North-Central of Iraq. Mitochondrial DNA Part A. 27(5), 3250-3254.

17. Komori, M. R., Ghosh, S., Takachi, S., Hu, Y., Mizoguchi, T., Koyama, Y., and Kuki, 1998. A Null Lesion in the Rhodopin 3,4-desaturase of Rhodospirillum rubrum Unmask a Cryptic Branch of the Carotenoid Biosynthetic Pathway. Biochemistry. 37: 8987-8994.

18. Kurnia, U., Agus, F., Adimihardja, A., dan Dariah, A. 2006. Sifat Fisik Tanah dan Metode Analisisnya. BBSDLP: Banjarmasin.

19. Lauriano, E. R., Faggio, C., Capillo, G., Spanò, N., Kuciel, M., Aragona, M., Pergolizzi, S., 2018. Immunohistochemical characterization of epidermal dendritic-like cells in giant mudskipper, Periophthalmodon schlosseri. Fish \& Shellfish Immunology. 74, 380-385

20. Looi, L. J., Aris, A. Z., Haris, H., Yusoff, F. Md., and Hasim, Z., 2016. The levels of mercury, methylmercury and selenium and the selenium health benefit value in grey-eel catfish (Plotosus canius) and giant mudskipper (Periophthalmodon schlosseri) from the Strait of Malacca. Journal of Chemospere.152, 265-273

21. Maggyvin, E. dan Sinuraya, R. K. 2017. Marijuana dan Autisme: Sebuah Literatur Review. Jurnal Farmaka. 15 (1): 70-92.
22. Mahadevan, G., Mohan, K., Vinoth, J., and Ravi, V., 2019. Biotic potential of mucus extracts of giant mudskipper Periophthalmodon schlosseri (Pallas, 1770) from Pichavaram, southeast coast of India. The journal of basic and applied zoology. 80(13).

23. Martin, K. L., 2013. Theme and variations: amphibious air-breathing intertidal fishes

24. Martínez, H. L., Agorreta, A., Sánchez, M. T., and Mauro, D, S., 2018. Evidence of positive selection suggests possible role of aquaporins in the water to land transition of mudskippers. Organisms Diversity and Evolution. 18(4), 499-414.

25. Moss, S.M. 1989. Effect of Exogenous Androgens on Growth, Biochemical Composition and Reproduction of the Coot Calm Mulinia literalis. Pac SCI.

26. Mohammed, A., and Imad, H., 2013. Autosomal STR: From locus information to next generation sequencing technology. Res. J. Biotechnol. 8(10):92-105.

27. Murdy, E.O., 1989. A taxonomic revision and cladistic analysis of the Oxudercine gobies (Gobiidae: Oxudercinae). Rec Aust Mus Suppl 11: 1-93.

28. Panda, L., and Mabalirajan, U., 2018. Recent updates on corticosteroid resistance in asthma. European Medical Journal. 3(3), 49-57.

29. Polgar, G., Ghanbarifardi, M., Milli, S., Agorreta, A., Aliabadia, M., Esmaeili, H. R., and Khang, T. F., 2017. Ecomorphological adaptation in three mudskippers (Teleostei: Gobioidei: Gobiidae) from the Persian Gulf and the Gulf of Oman. Hydrobiologia. 795(1), 91-111.

30. Prasad, K., Singh, M. B., and Ryan, H., 2016. Corticosteroids for managing tuberculous meningitis (Review). European Medical Journal. 3(3), 49-57.

31. Rajendran, P., Bharatidhasan, R., dan Sureshkumar, K. 2017. GC-MS Analysis of Phyto-Components in Raw and Treated Sugarcane Juice. Int.J,Curr.Microbiol.App.Sci. 6 (7): 51-61.

32. Rozaliyani, A., Susanto, A. D., Swidarmoko, B., dan Yunus, F. 2011. Mekanisme Resistens Kartikosteroid pada Asma. Jurnal Respir Indo. 31 (4): 210-223.

33. Ridho, M. R., Patriono, E., Sholikah, M., 2019. Food habits of three species of mudskippers in the Musi River Estuary, South Sumatra, Indonesia. Biodiversitas. 20(8), 2368-2374.

34. Salempa, P. dan Muharram, H. 2016. Senyawa Steroid dalam Tumbuhan Bayur. Badan penerbit UNM: Makasar.

35. Sari, M., 2012. Jenis Fauna Hutan Mangrove di Areal PT. Bina Ovivipari Semesta dan Sekitarnya. Penerbit PT. Bina Ovivipari Semesta: Pontianak.

36. Sun, J. 2007. D-Limonene: Safety and Clinical Aplication. Alternative Medicine Review. 12 (3): 259-264

37. Takeda, T., Hayashi, M., Toba, A., Soyano, K., and Ishimatsu, A., 2012. Ecology of the Australian 
mudskipper Periophthalmus minutus, an amphibious fish inhabiting a mudflat in the highest intertidal zone. Australian Journal of Zoology. 57: 312-320.

38. Wu, R. X., Hong, W. S., Zhang, Q. Y., Chen, S. X., 2009. Comparative enzyme activities of the intestinal brush border membranes of the herbivorous mudskipper Boleophthalmus pectinirostris and the carnivorous Chinese black sleeper Bostrichthys sinensis. Journal of Applied Ichthyology. 25, 571-575.

39. Yang, X, X., Gu, W., Liang, L., Yan, H, L., Wang, Y. F., Bi, Q., Zhang, T., Yu, J., and Rao, G. X., 2017.
Screening for the bioactive constituents of traditional Chinese medicines-progress and chalenges. Royal society of chemistry. 7, 3089-3100.

40. You, X, X., Sun, M., Li, J., Bian, C., Chen, J., Yi, Y., Yu, H., and Shi, Q., 2018. Mudskippers and Their Genetic Adaptations to an Amphibious Lifestyle.

41. Zaini, R. G., Brandt, K., Clench, M. R., dan Maitre, C. L. L. 2012. Effect of Bioactive Compounds from Carrots (Daucus carota L.), Polyacetylenes, Betacarotene and Lutein on Human Lymphoid Leukimia Cells. Medical Chemistry Journal. 12 (0): 2-13. 